\title{
Post-Secondary Student Mental Health and Well-being: a Systems and Intersectionality-Informed Approach
}

\author{
Nazilla Khanlou ${ }^{1}$ if \\ Published online: 19 June 2019 \\ C) Springer Science+Business Media, LLC, part of Springer Nature 2019
}

Youth mental health and well-being are important areas of scholarly, practice, and policy focus. Transformations taking place in societies across the globe in relation to changing family structures and gender roles, community and school involvement, expansion of social media into all aspects of life offer, and other social trends offer novel opportunities and pose new challenges for youth. Over the decades, a growing body of literature has examined the risk and protective factors for child and adolescent mental health (although less attention has been given to youth mental well-being and mental health promotion). However, up until recently, limited attention was given to youth who are transitioning into emerging adulthood in general, and their mental health in post-secondary settings in particular.

In 2017, I had the fortune of discussing with Professor Lesley Beagrie, Co-Chair of the Mental Health Steering Committee at York University, the idea of a journal special issue focused on post-secondary students' mental health. Dr. Beagrie has been central to the development of York University's mental health strategy (York University n.d.). Over the years, she has led campus-wide events and collaborative approaches across sectors (including secondary school partners) that initiate the conversation about mental health and well-being for students and work together to support students. I am also grateful that Dr. Masood Zangeneh, Senior Editor of the International Journal of Mental Health and Addiction, supported a special issue focused on post-secondary students' mental health, and facilitated the initiative through all phases under his senior editorial leadership.

Collectively, Dr. Beagrie, Dr. Zangeneh, and I placed the call out for manuscript submissions through our scholarly networks. We were encouraged by the immediate and continuing response to the call for this special issue. As evident from the compilation of articles in the issue, there is innovative, timely, and interdisciplinary scholarship developing on postsecondary students' mental health and well-being. Articles in the issue address the topic from different yet complementary angles, with implications for practice, education, policy, and structural support. The contributions also present the application of a range of empirical methodologies and diverse conceptual underpinnings in moving forward the scholarship of

Nazilla Khanlou

nkhanlou@yorku.ca; http://nkhanlou.info.yorku.ca

1 Women's Health Research Chair in Mental Health, Faculty of Health, School of Nursing, York University, HNES 3rd floor, 4700 Keele Street, Toronto, ON, Canada 
post-secondary student mental health and well-being. Several of the contributions in the issue are from post-secondary students as first authors. Some of the papers focus at the individuallevel attributes, other papers consider broader cultural factors, and others examine current emerging social and technology-related mental health influences. The special issue is part of a current wave of growing recognition of post-secondary students' mental health concerns. For example, the Mental Health Commission of Canada is leading the development of a National Standard for Psychological Health Safety of Post-Secondary Students (Mental Health Commission of Canada n.d.).

How do we bring together what we are learning from across research teams, institutionspecific strategies, national initiatives, and post-secondary students themselves on postsecondary student mental health and well-being? As scholars, we can become immersed in our silos of research and intention by focusing on individual-level factors or structurallevel interpretations. However, in real life, each student's individual lived experience matters, as do the changing socio-economic environments affecting their post-graduation opportunities and their current economic barriers and related health disparities. A systems perspective that recognizes the micro-level individual lived experiences and understands these within the context of students' meso-level influences (such as families, academic institutions, immediate communities), and macro-level trends (such as changing national socio-economic gradients, migration and growing diversities, racism, climate change, and digital literacy) can help provide a holistic and action-oriented perspective. Yet to arrive at equitable and anti-oppressive inter-sectoral and student-centered policies, strategies, and mental health-promoting actions, an intersectionality-informed understanding (Rosenthal 2016) is also needed. This lens helps in foregrounding student identities in the complex web of power (or lack of) and context as post-secondary students, during a transitional phase of life to which they (and their families) have committed significant resources.

As a newer post-secondary educator in the mental health field, in 2003, I wrote about fostering students' critical awareness of intersections through teaching a graduate course on youth mental health promotion (Khanlou 2003). Over fifteen years later, today, an intersectionality perspective is more prevalent - and continues to be just as relevant - for educators. Collectively, it helps us to understand the opportunities for post-secondary students' mental health promotion from a critical and comprehensive perspective, guiding action informed by knowledge that is grounded in students' lived experiences.

Guest Editor

Nazilla Khanlou

York University

May 2019

\section{Compliance with Ethical Standards}

Conflict of Interest The author declares that there is no conflict of interest.

Research Involving Human Participants This submission is the Editorial for the on Special Issue on PostSecondary Student Mental Health. It does not report on research involving human participants.

Informed Consent Informed consent was not required as this submission is an Editorial as per above. 


\section{References}

Khanlou, N. (2003). Mental health promotion education in multicultural settings. Nurse Education Today, 23(2), 96-103.

Mental Health Commission of Canada. National Standard for Psychological Health Safety of Post-Secondary Students: Frequently Asked Questions (FAQ). Available url: https://www.mentalhealthcommission. ca/sites/default/files/downloads/student_standard_faq_2018_eng.pdf. Accessed 31 May 2019.

Rosenthal, L. (2016). Incorporating intersectionality into psychology: an opportunity to promote social justice and equity. American Psychologist, 71(6), 474-485.

York University. Mental health strategy: advancing a mentally health campus. Available url: http://mhw.info. yorku.ca/. Accessed 31 May 2019.

Publisher's Note Springer Nature remains neutral with regard to jurisdictional claims in published maps and institutional affiliations. 